\title{
Potassium, calcium, and magnesium bridging of AOT to mica at constant ionic strength
}

\author{
Finian J. Allen ${ }^{\dagger}$ Chris L. Truscott, ${ }^{\dagger}$ Philipp Gutfreund, ${ }^{\ddagger}$ Rebecca J.L. Welbourn, \\ and Stuart M. Clarke, ${ }^{* \dagger}$ \\ $\dagger$ Department of Chemistry and BP Institute, University of Cambridge, Cambridge, Cambs, \\ CB2 $1 E W, U K$ \\ $\ddagger$ Institut Laue Langevin, 71 avenue des Martyrs, Grenoble 38000, France \\ ฯISIS Pulsed Neutron Facility, Harwell Science and Innovation Campus, STFC, \\ Rutherford Appleton Laboratory, Didcot, Oxon, OX11 OQX, UK \\ E-mail: stuart@bpi.cam.ac.uk
}

\begin{abstract}
The bridging effect of a series of common cations between the anionic mica surface and the AOT anion has been studied in a condition of constant ionic strength and surfactant concentration. It was found that sodium ions did not show any bridging effect in this system; however, calcium, magnesium, and potassium all caused adsorption of the organic to the mica surface. The concentrations at which bridging occurred was probed, revealing that only a very low bridging cation concentration was required for binding. The bridged layer stability was also investigated and the interaction was shown to be a weak one, with the bound layer in equilibrium with the species in the bulk and easily removed. Even maintaining ionic strength and bridging ion concentration was not sufficient to retain the layer when the free organic in solution was removed.
\end{abstract}




\section{Introduction}

Adsorption behaviour at interfaces governs many natural and industrial processes, and as such gaining greater understanding of these processes is of considerable academic and commercial importance. Electrostatic interactions frequently play a key role in determining adsorption behaviour, and there are numerous examples of studies into adsorption of charged surfactants onto oppositely charged surfaces. ${ }^{1}$ It has been found that adsorption of anionic surfactants on surfaces of the same charge can in fact occur when certain cations are present; this has been described as cation 'bridging'. It was assumed that only divalent (or higher valency) ions could lead to this 'bridging' and that monovalent ions would not cause binding. Numerous examples of divalent ions bridging have been reported, including on silica, ${ }^{2}$ mica ${ }^{3}$ and montmorillonite. ${ }^{4}$ This form of binding has been suggested as a mechanism of crude oil adsorption onto mineral surfaces. ${ }^{5}$

We have recently shown that it is also possible for monovalent ions to facilitate adsorption between an anionic surfactant and an anionic surface. ${ }^{6}$ It was experimentally observed that the monovalent $\mathrm{Cs}^{+}$caused binding between the anionic mica surface and the organic aerosolOT anion (AOT, sodium bis(2-ethylhexyl) sulfosuccinate), and it was suggested that it was the relatively large ionic radius and associated lowered charge density and weaker hydration of the $\mathrm{Cs}^{+}$ion that allow it to bridge.

In this work the surfactant AOT has again been used to investigate selective ion binding behaviour. The structure of AOT is given in Figure 1; the key group involved in the bridging interaction is the sulphonate anion. This surfactant has been used extensively in the literature ${ }^{7}$ including for prior work into cation binding ${ }^{2,3,6,8}$ in part because the counterion may be exchanged using the methods of Eastoe et al. ${ }^{9}$. Previous studies into cation binding have utilised the pure AOT salt of the cation under investigation. In commercially relevant systems however, there will often be multiple cations competing for the surface and organic species. Ion exchange of AOT is also a non-trivial process and adds complexity, as well as the possibility of introducing surface active hydrolysis products of the AOT. In this work 
we have utilised the readily available sodium AOT salt at a fixed concentration and added other cations of interest into solution.

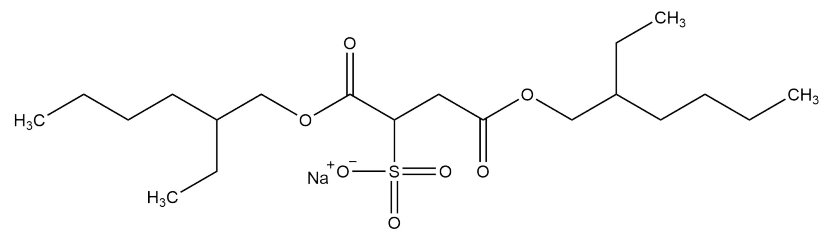

Figure 1: Structure of sodium bis(2-ethylhexyl) sulfosuccinate, NaAOT.

Behaviour at the surfaces of clay minerals is of particular interest in oil recovery, as clays are present in many sandstone reservoirs and can be pore lining ${ }^{10}$ meaning that this is the mineral actually in contact with the oil. There is also evidence that the presence of clays is linked to which reservoirs show incremental recovery from lowered salinity water flooding. ${ }^{11}$ Muscovite mica provides a convenient model system for the basal surface of clay minerals. Mica has been utilised extensively as a substrate for many surface techniques due to the perfect basal cleavage that the crystal exhibits. This can yield surfaces which are atomically flat over the order of square centimetres in area. ${ }^{12}$ Mica carries a negative surface charge from isomorphic substitution of $\mathrm{Si}^{4+}$ by $\mathrm{Al}^{3+}$ in the tetrahedral layer of the mineral, giving a negative charge site per $47 \AA^{2}$ area. ${ }^{13}$ In the natural material this charge is compensated by $\mathrm{K}^{+}$present between the mica sheets and on the exposed basal surfaces. In aqueous solution these ions can dissociate or be exchanged for other cations.

Probing behaviour at buried interfaces is a complex problem which requires specialised techniques. Introducing an external probe, such as in atomic force microscopy, has the potential to perturb the system either by inducing ordering through 'frontal confinement' ${ }^{14,15}$ or by removal of transiently bound species. Neutron and X-ray reflectivity are well established techniques which can be used to gain information about buried interfaces in a specific and non-invasive manner. ${ }^{16}$ The contrast between hydrogen and deuterium as seen with neutrons makes this the preferred technique for hydrocarbon surfactant systems. Historically reflectivity from mica has been complicated by attenuation of neutrons by the mica structure, and waviness in unsupported crystals. For X-ray reflectivity this waviness issue was over- 
come by the innovative bent-crystal mounting system of Briscoe et al. ${ }^{17}$, though significant complication is added to the data analysis by this set-up. The method of Browning et al. ${ }^{18}$, using a mica crystal supported on a polished silicon wafer, has since been shown to provide a reliable mounting option for neutron reflectivity and it is the one used in this work.

\section{Experimental}

\section{Materials}

Sodium chloride (Sigma-Aldrich, $\geq 99.5 \%$ ), calcium chloride dihydrate (Sigma-Aldrich, $\geq 99 \%$ ), magnesium chloride hexahydrate (Sigma-Aldrich, $\geq 99 \%$ ), potassium chloride (Sigma-Aldrich, $\geq 99 \%$ ) and sodium bis(2-ethylhexyl) sulfosuccinate, NaAOT, (Sigma-Aldrich, $\geq 99 \%$ ) were used as received. All solutions were made up in $\mathrm{D}_{2} \mathrm{O}$ supplied by the ILL and ISIS facilities (Sigma-Aldrich, 99.9 atom \% D). Solutions of reagents were prepared at higher concentrations, but all well below the respective solubility limits, and pumped and mixed or diluted using an HPLC pump to give the desired concentrations in the cell. Solubilities of all resultant solutions were checked prior to the experiment and no precipitation or turbidity was visible in any case.

High quality sheets of clear ruby muscovite mica, $25 \mu \mathrm{m}$ by $100 \mathrm{~mm}$ by $50 \mathrm{~mm}$, were supplied by Attwater and Sons Ltd. Silicon wafers, n-typed doped with crystallographic orientation (111) and dimensions $10 \mathrm{~mm}$ by $100 \mathrm{~mm}$ by $50 \mathrm{~mm}$, polished to a roughness of $\leq 5 \AA$ were purchased from Crystran.

\section{Reflectivity substrate preparation}

Substrates for neutron reflectivity measurements were prepared using the method of Browning et al. ${ }^{18}$, with the modification of Griffin et al. ${ }^{19}$ to a larger substrate size. The preparation is only described in brief here. A low viscosity UV-curable glue (Loctite 3301) was spin coated onto a highly polished silicon wafer which had been nitric acid cleaned. A mica sheet 
was cleaved with adhesive tape and clamped against the glue layer by a highly polished Pyrex block (OptoSigma). The glue was cured with a UV lamp (UVP CL-1000, $\lambda 254 \mathrm{~nm}$ ) and the mica was cleaved again to yield a fresh top surface. This was $\mathrm{UV} / \mathrm{O}_{3}$ cleaned (BioForce Nano) for 20 minutes, then clamped against a teflon trough to form the reflectivity cell.

The cell was initially filled with care by hand, to avoid trapping bubbles, and subsequent solution exchanges were carried out with an HPLC pump using a volume of $30 \mathrm{ml}$ and a flow rate of $2 \mathrm{ml} / \mathrm{min}$. Previous work has shown this to be more than sufficient for complete exchange of the cell solution. HPLC lines were flushed between different solutions to avoid contamination.

\section{Neutron reflectivity measurements}

Neutron reflectivity measurements were carried out on the D17 reflectometer ${ }^{20}$ at the Institut Laue-Langevin, Grenoble, and the OFFSPEC reflectometer ${ }^{21}$ at the ISIS neutron facility, Oxfordshire . At D17 incident angles of $0.8^{\circ}$ and $3.2^{\circ}$ were chosen to cover the necessary range in momentum transfer normal to the surface, defined as $Q_{z}=\frac{4 \pi}{\lambda} \sin (\theta)$ where $\lambda$ and $\theta$ are the wavelength and incident angle of the neutron respectively. Due to the narrower wavelength distribution at OFFSPEC three angles were used to cover the desired range in $Q_{z}$ for these measurements; $0.3^{\circ}, 0.9^{\circ}$, and $2.3^{\circ}$. Both instruments were operated in timeof-flight mode, using the time taken for the neutron to reach the detector to determine the wavelength of neutrons in a pulse produced either by choppers or the spallation process.

\section{Reflectivity Data Analysis}

Data collected on the two instruments was processed in the usual manner. The 'coherent summation' method of Cubitt et al. ${ }^{22}$, implemented in the data reduction software COSMOS, ${ }^{23}$ was utilised on the data from D17 to allow for a small degree of curvature of the mica

surface, and for OFFSPEC data was reduced in Mantid. ${ }^{24}$ For D17 a region of the multidetector outside the specular condition was used to subtract the background from the data. 
Any remaining background was accounted for during data fitting, as was the background in data collected on OFFSPEC.

Due to slight imperfections away from the idealised crystal structure of the natural mica mineral the classically forbidden half Bragg peak at $0.32 \AA^{-1}$ is visible for some substrates. In these cases the data was truncated at $0.24 \AA^{-1}$, just below the onset of the peak, for the purposes of fitting to avoid contribution from the Bragg peak to the fitting routine. The full reflectivity profiles are still displayed in figures.

Neutron reflectivity data is conventionally fitted using a model consisting of a series of layers, each of which is characterised by a scattering length density (SLD), thickness, and roughness. In the substrates used in this work the glue and mica layers are thicker than the coherence length of the neutrons. This results in the need for a different analysis approach where for these 'thick' layers the sum of the intensity of the waves passing through the layers must be considered, rather than the sum of the amplitudes of the waves as is the case for 'thin' layers such as the silicon oxide layer. Due to this added complexity, data fitting was carried out using a custom routine based on the I-CALC program, the specifics of which are described in detail elsewhere. ${ }^{18}$ This routine also deals appropriately with the wavelength and path length dependent attenuation of the neutron beam in the glue and mica.

The SLD of a material may be calculated from the volume average of the sum of the scattering lengths of the nuclei present. Molecular volume may be estimated from the bulk density of a material. During data fitting the volume fraction of solvent inclusion in a layer may be found, by allowing the SLD of that layer to vary between the SLD of the pure solvent and that of the unhydrated layer. Scattering length densities of the materials used in this work are given in Table 1.

It is noted that the structures fitted to adsorbed layers in this work are based on fitting of only one contrast in each case, and are not necessarily a unique fit to the data. However, the primary conclusions of this work do not depend on the specifics of the layer structures. 
Table 1: Scattering Length Densities of Materials.

\begin{tabular}{lclc}
\hline Material & SLD $/ \times 10^{-6} \AA^{-2}$ & Material & SLD $/ \times 10^{-6} \AA^{-2}$ \\
\hline Silicon & 2.07 & $\mathrm{D}_{2} \mathrm{O}$ & 6.30 \\
Silicon oxide & 3.49 & $\mathrm{CMMi}^{\dagger}$ & 3.79 \\
Glue & 1.08 & $\mathrm{KAOT}$ & $0.65^{\ddagger}$ \\
Mica & 3.79 & $\mathrm{Ca}(\mathrm{AOT})_{2}$ & $0.63^{\ddagger}$ \\
$\mathrm{H}_{2} \mathrm{O}$ & -0.56 & $\mathrm{Mg}(\mathrm{AOT})_{2}$ & $0.64^{\ddagger}$ \\
\hline
\end{tabular}

$\dagger$ CMMi refers to water contrast matched to the mica substrate, to aid fitting of the silicon, silicon oxide, and glue layers. $\ddagger$ The SLD values for the respective AOT salts are computed based on a molecular volume of $641 \AA^{3}$ for NaAOT, ${ }^{6}$ as calculated from the bulk density, and the assumption that the metal cation takes up a small enough volume that cation exchange does not change the overall volume. This assumption extends to divalent ions where there are two AOT anions per cation.

\section{Results}

For adsorption measurements the concentration of $\mathrm{AOT}^{-}$was fixed at the critical micelle concentration (CMC) of the sodium salt of AOT, 2.5 mM. ${ }^{25}$ To allow a comparison between added cations, the initial concentrations of non-sodium inorganic salts added to the AOT solution was matched to the CMC of the pure AOT salt of that cation. For example the added $\left[\mathrm{Ca}^{2+}\right]$ was $0.5 \mathrm{mM}$ as the $\mathrm{CMC}$ of $\mathrm{Ca}(\mathrm{AOT})_{2}$ is $0.5 \mathrm{mM}$. The CMCs of the different AOT salts of the cations used are given in Table 2.

Table 2: CMCs of relevant AOT salts.

\begin{tabular}{lc}
\hline \multicolumn{1}{c}{ AOT salt } & CMC / mM \\
\hline NaAOT & $2.5^{25}$ \\
KAOT & $2.8^{26}$ \\
$\mathrm{Ca}(\mathrm{AOT})_{2}$ & $0.5^{27}$ \\
$\mathrm{Mg}(\mathrm{AOT})_{2}$ & $1.25^{28}$ \\
\hline
\end{tabular}

As ionic strength can affect adsorption characteristics, particularly for ionic surfactants, it was decided to maintain a consistent ionic strength throughout, as defined by $\mathrm{I}=\frac{1}{2} \sum_{i} c_{i} z_{i}^{2}$ where $c_{i}$ and $z_{i}$ are the concentration and charge of ion $i$ respectively. This would give certainty that any effects shown were due to the nature of the cations present and not 
an ionic strength change. Using NaAOT at $2.5 \mathrm{mM}$ and adding $\mathrm{MgCl}_{2}$ up to the $\mathrm{CMC}$ of $\mathrm{Mg}(\mathrm{AOT})_{2}$ resulted in an ionic strength of $6.25 \mathrm{mM}$, so this ionic strength was used consistently. Ionic strength was controlled where required with the addition of $\mathrm{NaCl}$.

\section{Characterisation of the mica surface}

A bare mica substrate was first characterised in three water contrasts. Fitted parameters co-refined to the three datasets are shown in Table 3, and the reflectivity data and fits are shown in Figure 2. The fitted values are physically reasonable, and in line with those from previous studies. ${ }^{29}$

Table 3: Fitted parameters for bare mica surface.

\begin{tabular}{lcc}
\hline Material & Thickness & Roughness $/ \AA$ \\
\hline Silicon & & $4 \pm 2$ \\
Silicon oxide & $15 \pm 2 \AA$ & $4 \pm 2$ \\
Glue & $14 \pm 1 \mu \mathrm{m}$ & $15 \pm 3$ \\
Mica & $18 \pm 1 \mu \mathrm{m}$ & $5 \pm 2$ \\
\hline
\end{tabular}

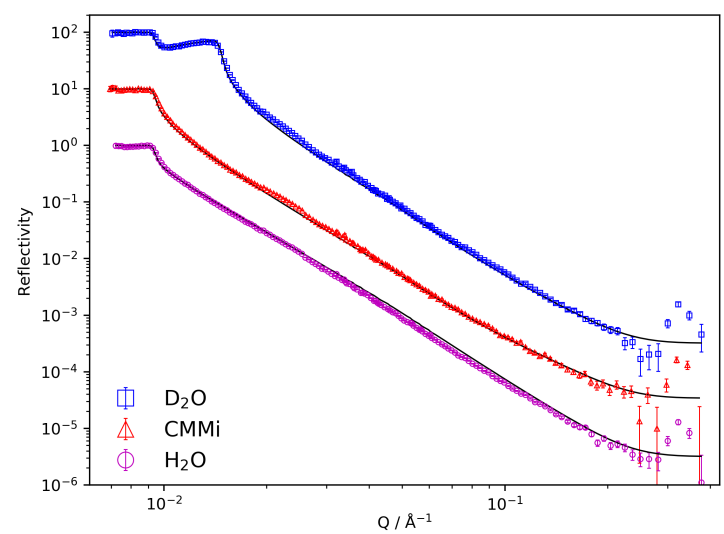

Figure 2: Reflectivity profiles of the bare mica surface in $\mathrm{D}_{2} \mathrm{O}$ (blue, offset by factor of 100), CMMI (water contrast matched to mica) (red, offset by factor 10), and $\mathrm{H}_{2} \mathrm{O}$ (magenta). 


\section{NaAOT with elevated ionic strength}

NaAOT at the CMC $(2.5 \mathrm{mM})$ was then introduced to the mica surface and the sample remeasured. No change in reflectivity was observed compared to the bare surface in $\mathrm{D}_{2} \mathrm{O}$ indicating no adsorption, which is consistent with prior observations. ${ }^{3}$ NaAOT with added $\mathrm{NaCl}$, to raise the ionic strength to $6.25 \mathrm{mM}$, was then introduced and again no adsorption was observed. These results are shown in Figure 3.

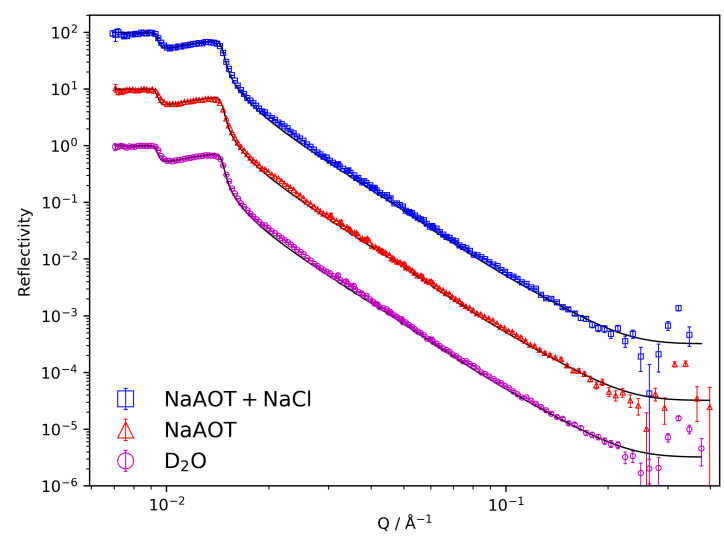

Figure 3: Reflectivity profiles of mica exposed to NaAOT with ionic strength raised to 6.25 $\mathrm{mM}$ by $\mathrm{NaCl}$ addition (blue, offset by factor of 100), NaAOT (red, offset by factor 10), and $\mathrm{D}_{2} \mathrm{O}$ (magenta).

Different mica samples were used for each of the three additional cations investigated to prevent any uncontrolled effects of salt history on the surface behaviour. The lack of any adsorption of NaAOT at raised ionic strength was verified on every mica crystal used.

\section{Calcium bridging}

When a solution of NaAOT at $2.5 \mathrm{mM}$ with added $\mathrm{CaCl}_{2}$ at $0.5 \mathrm{mM}$ and $\mathrm{NaCl}$ at 2.25 $\mathrm{mM}$ (to fix the ionic strength at $6.25 \mathrm{mM}$ ) was introduced to the mica surface a clear change in reflectivity profile was observed, indicating adsorption of some material, as given in Figure 4. A single layer model could not be fitted to the data, but it was found that a structure consisting of a water layer between the mica surface and an unhydrated surfactant 
layer closely reproduced the observed data. Reflectivity data with calculated fits and the associated SLD profile are shown in Figure 4.

As it has been shown that the $\mathrm{Na}^{+}$counter ion of the $\mathrm{AOT}^{-}$does not lead to a bridging interaction, adsorped species have been referred to as the AOT salt of the bridging counterion in question. For example the adsorped species from a solution of $\mathrm{NaAOT}$ with added $\mathrm{CaCl}_{2}$ is referred to as $\mathrm{Ca}(\mathrm{AOT})_{2}$.

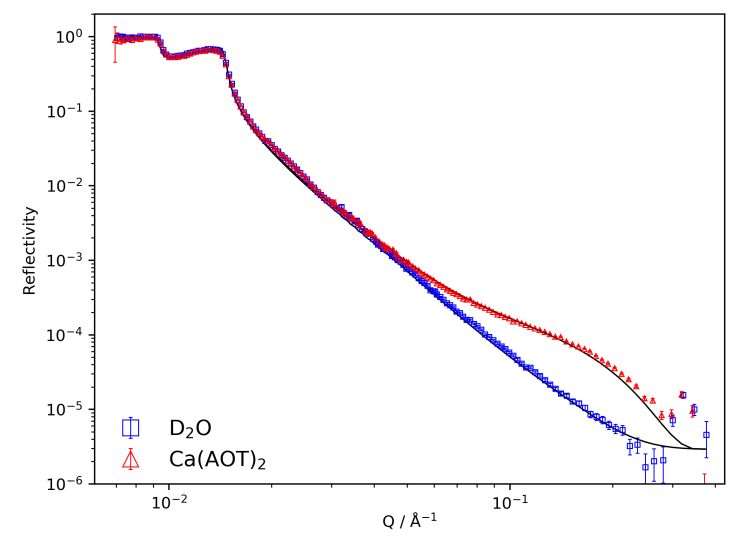

(a)

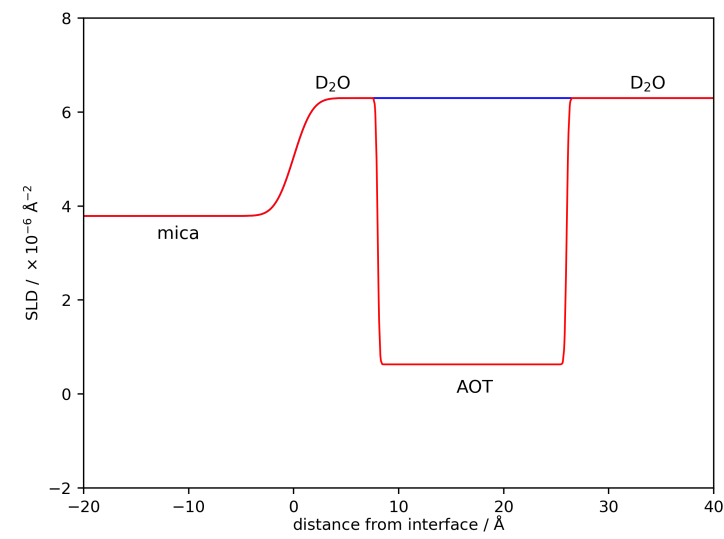

(b)

Figure 4: Reflectivity profiles for the mica surface in $\mathrm{D}_{2} \mathrm{O}$ (blue) and when $\mathrm{Ca}(\mathrm{AOT})_{2}$ had adsorbed (red) (Figure 4a), and SLD profile of the fitted layer structure (Figure 4b).

Table 4: Fitted parameters for $\mathrm{Ca}^{2+}$ bound structure.

\begin{tabular}{lcccc}
\hline Layer & SLD $/ \times 10^{-6} \AA^{-2}$ & Thickness $/ \AA$ & Roughness $/ \AA$ & Hydration $/ \%$ \\
\hline Water & 6.30 & $8 \pm 2$ & $1 \pm 1$ & - \\
$\mathrm{Ca}(\mathrm{AOT})_{2}$ & 0.63 & $18 \pm 1$ & $1 \pm 1$ & $0 \pm 3$ \\
\hline
\end{tabular}

\section{Magnesium bridging}

A fresh mica surface was characterised as before in three water contrasts. Fits to the data and model parameters are shown in Supplementary Information Figure S1 and Table S1. NaAOT at $2.5 \mathrm{mM}$ with $\mathrm{MgCl}_{2}$ at $1.25 \mathrm{mM}$ was introduced to the cell and the reflectivity profile measured. Again a large change was visible, indicating adsorption of an organic layer. 
Various models were considered during data fitting, and the least complex model which could replicate the experimental results was found to be a four layer fit consisting of a water layer adjacent to the mica, followed by two surfactant layers with an intervening water layer. In this fit the thicknesses of the two surfactant layers were constrained to be the same.

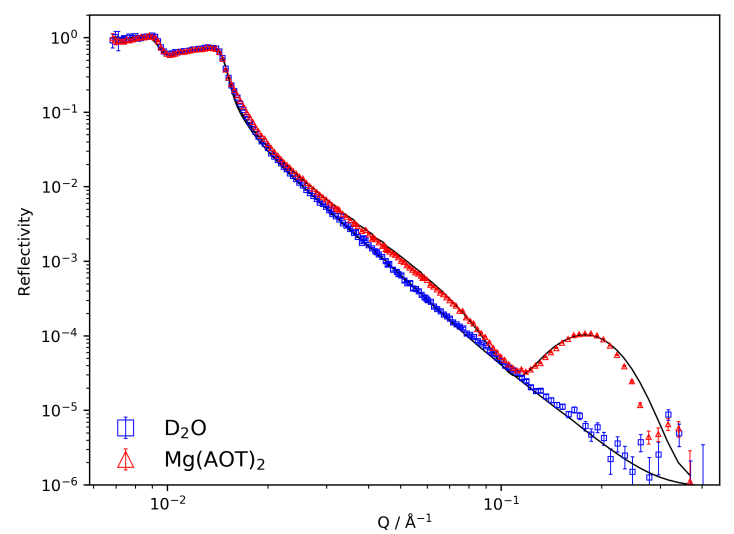

(a)

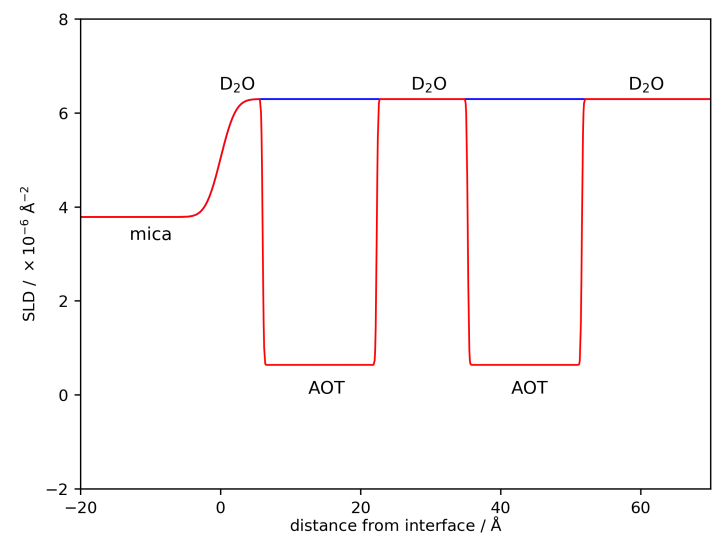

(b)

Figure 5: Reflectivity profiles for the mica surface in $\mathrm{D}_{2} \mathrm{O}$ (blue) and when $\mathrm{Mg}(\mathrm{AOT})_{2}$ had adsorbed (red) (Figure 5a), and SLD profile of the fitted layer structure (Figure 5b).

Table 5: Fitted parameters for the $\mathrm{Mg}^{2+}$ bound structure.

\begin{tabular}{lcccc}
\hline Layer & SLD $/ \times 10^{-6} \AA^{-2}$ & Thickness $/ \AA$ & Roughness $/ \AA$ & Hydration $/ \%$ \\
\hline Water & 6.30 & $6 \pm 1$ & $1 \pm 1$ & - \\
$\mathrm{Mg}(\mathrm{AOT})_{2}$ & 0.64 & $16 \pm 1$ & $1 \pm 1$ & $0 \pm 5$ \\
Water & 6.30 & $13 \pm 1$ & $1 \pm 1$ & - \\
$\mathrm{Mg}(\mathrm{AOT})_{2}$ & 0.64 & $16 \pm 1$ & $1 \pm 1$ & $0 \pm 5$ \\
\hline
\end{tabular}

After layer removal, discussed in more detail later, introducing the same solution back to the cell resulted in a very similar reflectivity profile to the initial layer, showing repeatability and reversibility of this adsorption process. The reflectivity profiles from the initially formed layer and after desorption then readsorption are shown in Figure 6. 


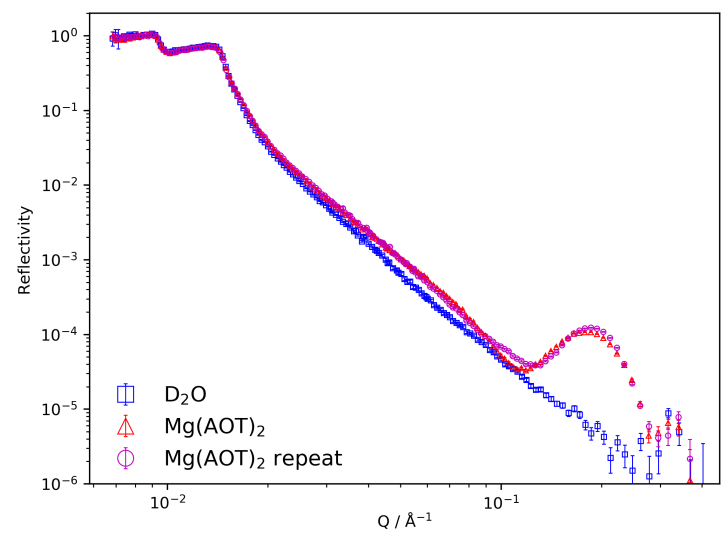

Figure 6: Reflectivity data of the initial $\mathrm{Mg}(\mathrm{AOT})_{2}$ layer (red) and after readsorption (magenta), revealing a very similar profile. Bare mica in $\mathrm{D}_{2} \mathrm{O}$ is shown for comparison (blue).

\section{Potassium bridging}

A further new mica surface was again fully characterised, with fits and parameters given in Supplementary Information Figure S2 and Table S2. NaAOT at $2.5 \mathrm{mM}$, with $\mathrm{KCl}$ at 2.8 $\mathrm{mM}$ and $\mathrm{NaCl}$ at $0.95 \mathrm{mM}$ was introduced to the cell. The measured reflectivity is shown in Figure 7a and again layer formation was seen, though a different adsorbate structure is evident from the reflectivity profile when compared to the other cations.

Table 6: Fitted parameters for the $\mathrm{K}^{+}$bound structure.

\begin{tabular}{lcccc}
\hline Layer & SLD $/ \times 10^{-6} \AA^{-2}$ & Thickness $/ \AA$ & Roughness $/ \AA$ & Hydration $/ \%$ \\
\hline KAOT & 0.65 & $18 \pm 2$ & $1 \pm 1$ & $0 \pm 3$ \\
\hline
\end{tabular}

The fit could be improved moderately by adding a water layer between the mica and AOT with a thickness of $2-3 \AA$, although this is less than the roughness associated with the mica surface and so it was not deemed a reasonable parameter to include.

\section{Concentration dependence of calcium bridging}

The concentration at which bridging still occurred in the calcium system was further probed. The same mica crystal which had been used for $\mathrm{Ca}(\mathrm{AOT})_{2}$ adsorption was utilised, after layer 


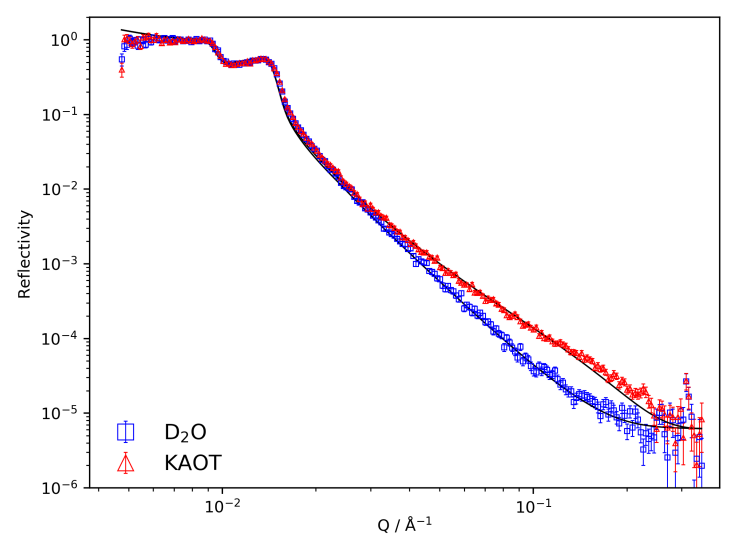

(a)

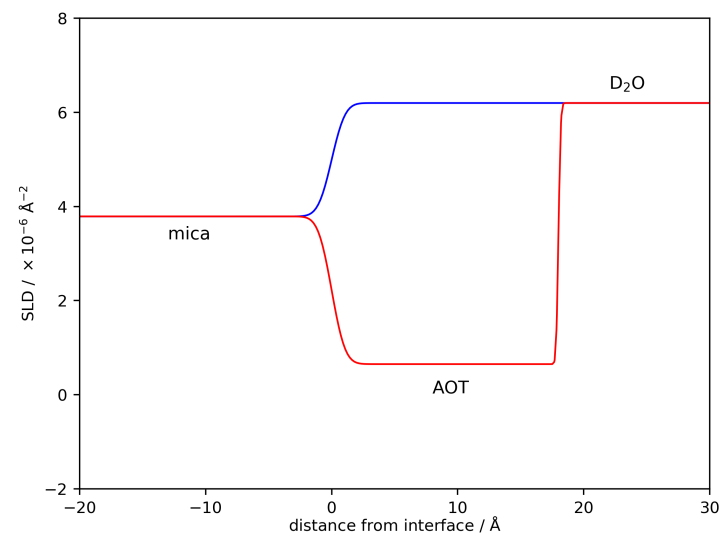

(b)

Figure 7: Reflectivity profiles for the mica surface in $\mathrm{D}_{2} \mathrm{O}$ (blue) and when KAOT had adsorbed (red) (Figure 7a), and SLD profile of the fitted layer structure (Figure 7b).

desorption and exchange of the cell into $\mathrm{D}_{2} \mathrm{O}$. Using a concentration of $\mathrm{Ca}^{2+}$ reduced to 0.05 $\mathrm{mM}, 10 \%$ of the initial value used, while maintaining the same ionic strength and concentration of $\mathrm{AOT}^{-}\left(\left[\mathrm{CaCl}_{2}\right]=0.05 \mathrm{mM},[\mathrm{NaAOT}]=2.5 \mathrm{mM},[\mathrm{NaCl}]=3.6 \mathrm{mM}\right)$ resulted in an essentially identical reflectivity profile as at the initial calcium concentration for layer adsorption. This shows that the same structure adsorbs even at this much reduced concentration of the bridging ion. Concentrations of $\mathrm{Ca}^{2+}$ below $0.05 \mathrm{mM}$ were not tested.

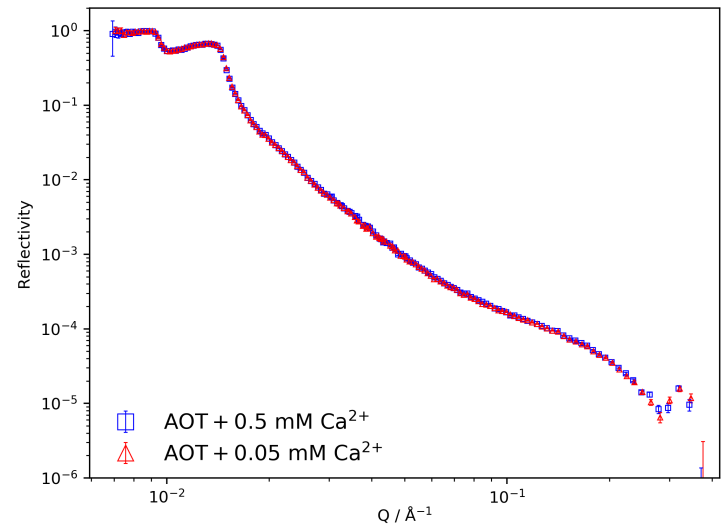

Figure 8: Reflectivity profiles from the mica exposed to the initial solution concentration of $\mathrm{Ca}^{2+}$ (blue) and identical profile produced when $\left[\mathrm{Ca}^{2+}\right]$ was reduced to $0.05 \mathrm{mM}, 10 \%$ of the initial value (red). The same structure is clearly present in both cases. 


\section{Layer removal}

To probe the stability and strength of binding of the adsorbed layers, the desorption behaviour of both the calcium and magnesium bridged structures was studied. In both cases the cell solution from which bridging was observed was directly exchanged to a solution of the same ionic strength (controlled with $\mathrm{NaCl}$ ) and same concentration of calcium or magnesium respectively, but without any AOT. In both cases the reflectivity profile returned to that of the bare mica substrate, as shown in Figure 9, revealing complete desorption of any organic from the surface.

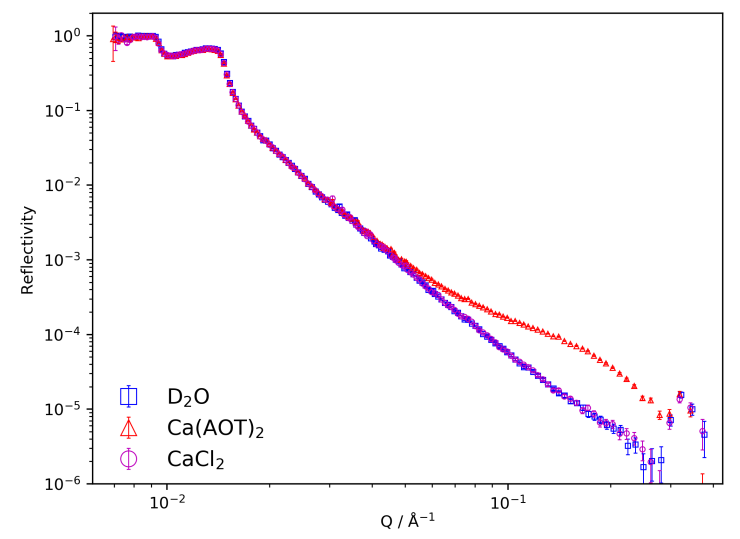

(a)

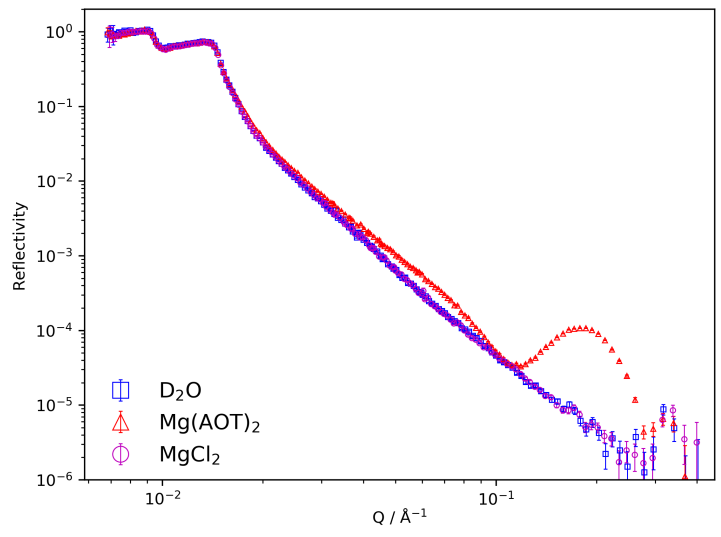

(b)

Figure 9: Data showing the complete desorption of bound layer structures when the solution was exchanged to a solution of the same ionic strength and binding ion concentration but with no AOT. Calcium binding is shown in Figure 9a and magnesium binding in Figure 9b.

\section{Discussion}

\section{Ion dependent bridging interactions}

This work builds on previous investigations into the question of which cations are capable of binding anionic molecules to an anionic surface. While magnitude of charge clearly plays a role in determining this behaviour, the charge density of the cation also appears to be 
important. Within the monovalent ions, we have previously shown that the relatively large and less well hydrated $\mathrm{Cs}^{+}$ion was capable of binding ${ }^{6}$ whereas the higher charge density and more hydrated $\mathrm{Na}^{+}$did not, with these measurements conducted at the CMC of the relevant ion. It was postulated that as Group 1 is ascended and the charge density increases, there will be some break point at which ions no longer cause binding. By showing that $\mathrm{K}^{+}$also causes cation mediated binding whereas $\mathrm{Na}^{+}$does not, even with increased $\left[\mathrm{Na}^{+}\right]$ relative to the pure NaAOT salt, we have further localised the point in Group 1 at which this occurs to between $\mathrm{K}^{+}$and $\mathrm{Na}^{+}$. Tetraalkylammonium ions with longer side chains, having even larger ionic radii and lower hydration energies, might also be expected to bridge, in a manner analogous to their effect on swelling of clay minerals.

In all the fitted structures the surfactant layer thickness is of the order of the measured monolayer thickness of $\sim 18 \AA .{ }^{25,30}$ The mica surface is hydrophilic, and it would be energetically unfavourable for the surfactant molecules to order such that the hydrophobic tails are all oriented towards either the mica or to water. We therefore suggest that while the structures are essentially monolayers based on the thickness parameters, there will be significant disorder and different orientation of the molecules to allow head groups to be present on both sides of each unhydrated surfactant layer. More complex fitting models consisting of separated surfactant head and tail regions could present slightly thicker adsorbed layers, with solvated head groups more closely matching the solvent SLD, but the simplest model consistent with the experimental data was adopted. The added ionic strength will lead to a reduced Debye length from greater screening between charged species, and could therefore influence closer packing than has been seen in some pure salt solutions where bilayer thicknesses have been observed in the range 31 - $38 \AA$ for the calcium system. ${ }^{2,3}$ Dense packing is also consistent with the unhydrated nature of the layer from the fits to the data.

In the studied regime we see multilayering only from $\mathrm{Mg}^{2+}$, and not from $\mathrm{Ca}^{2+}$ or $\mathrm{K}^{+}$. The phenomenon of multilayering at the air/solution interface has been extensively reviewed by Thomas and Penfold ${ }^{31}$, and using their nomenclature the structure formed in the added 
magnesium case may be referred to as a $S_{2}$ structure. For the solution/mica interface the hydrophilic nature of the surface will favour a more bilayer like first adsorbed structure in contrast to the air/water interface, but behaviour of subsequent layers might be expected to be similar in the two cases. It has been shown previously that $\mathrm{Ca}(\mathrm{AOT})_{2}$ can form multilayered structures on mica at the $\mathrm{CMC}(0.5 \mathrm{mM})$ with up to four bilayers and intervening water, and significantly more layers at twice the CMC. ${ }^{3}$ In the system studied here the $\mathrm{Ca}^{2+}$ concentration is the same as in that work, but the [AOT- $]$ is higher in our case, at 2.5 $\mathrm{mM}$. The presence of additional adsorped layers for magnesium addition may be due to the ratio between cation:[AOT $\left.{ }^{-}\right]$being approximately that required for charge neutrality at 1.25 $\mathrm{mM}: 2.5 \mathrm{mM}$ (as would be present in the pure $\mathrm{Mg}(\mathrm{AOT})_{2}$ salt), when compared to $0.5 \mathrm{mM}: 2.5$ $\mathrm{mM}$ for the added calcium case. If this ratio is key in determining multilayer formation then it might be expected that further increasing the calcium concentration to $1.25 \mathrm{mM}$ might induce this behaviour, subject to the constraints of solubility. No multilayering is observed in the added potassium case despite the relative concentrations of potassium and [ $\left.\mathrm{AOT}^{-}\right]$ being close to charge neutrality (2.8 mM:2.5 mM), but it may be the case that multivalent ions are a necessary condition for multilayer formation. ${ }^{32,33}$ Multilayering is clearly a process sensitive to multiple factors, and our conclusions are focussed on the presence or absence of adsorption rather than the specifics of the structures.

Molecular dynamics simulations by Kobayashi et al. ${ }^{34}$ suggested that $\mathrm{Na}^{+}$and $\mathrm{Mg}^{2+}$ would bind organic acids to mica via a water mediated interaction, whereas $\mathrm{K}^{+}$and $\mathrm{Ca}^{2+}$ would bridge directly. Our results are not fully consistent with these findings in that a water layer was required to satisfactorily fit the structure of the $\mathrm{Ca}^{2+}$ bound layer, and even at elevated concentrations $\mathrm{Na}^{+}$was never found to bridge. The simulations did however propose that the $\mathrm{Na}^{+}$binding strength was the weakest of the ions investigated. The sulfonate head group of AOT may also differ in behaviour to an acid, as discussed in more detail later. Consistent with the simulation, we did find that the $\mathrm{K}^{+}$layer appeared to have little if any water layer between the mica and surfactant. Our suggestion for the mechanism of cation 
bridging is one in which the surface charge sites, cations, and anionic head group must all lose some degree of hydration to come together and bridge. The multivalent cations will be more strongly solvated by the water molecules, and if only partial loss of hydration of the cation occurs on bridging then a water/ion layer would be expected. The thicknesses fitted to the water layers for the added magnesium and calcium case are of the order of a few water molecules, which is consistent with this model.

At the lowest $\mathrm{Ca}^{2+}$ experimentally tested $(0.05 \mathrm{mM})$ the ratio of $\mathrm{Na}^{+}: \mathrm{Ca}^{2+}$ is greater than 100:1 and yet binding of a layer to the mica is still observed. Clearly the relative affinity of the $\mathrm{Ca}^{2+}$ for both the mica and the $\mathrm{AOT}^{-}$ion is so great that it can successfully out-compete the $\mathrm{Na}^{+}$. The relative concentrations at which this is no longer the case will be the subject of future study. Whether $\mathrm{AOT}^{-}$adsorped to a mica surface which had previously been exposed to $\mathrm{Ca}^{2+}$, when no additional bridging cations where present in solution, was not investigated. There have been suggestions that multivalent ions can adsorb to mica in sufficient quantities to over-compensate the surface charge and lead to a charge inversion, ${ }^{35}$ however de Poel et al. ${ }^{36}$ showed that exchange of mica with $\mathrm{CaCl}_{2}$ followed by pure water did not lead to over-exchange of $\mathrm{Ca}^{2+}$ onto the surface. Without over-exchange it seems unlikely that $\mathrm{AOT}^{-}$would adsorp in the absence of additional bridging ions.

\section{Relevance to low salinity oil recovery}

We have already shown that the proffered explanation of oil release by exchange of divalent 'bridging' ions for monovalent ions incapable of bridging is not a full description, with the observation of monovalent $\mathrm{Cs}^{+}$binding organic anions to mica. Here we have shown that $\mathrm{Cs}^{+}$is not unique in this ability as a monovalent ion but in fact the $\mathrm{K}^{+}$ion shows the same effect. Although not confirmed experimentally, we assume that the intermediate ion $\mathrm{Rb}^{+}$, between $\mathrm{K}^{+}$and $\mathrm{Cs}^{+}$, will also act as a 'bridge'. This is industrially important as it provides further evidence that the specific cations present, rather than the total salinity or monovalent and divalent concentrations, are important for water flooding. Secondary water-flooding 
generally occurs using either sea-water or water from aquifers; in both cases potassium can be present in concentrations at least equivalent to the calcium concentration. ${ }^{37}$ If efforts are made to remove only the divalent ions before enhanced recovery then cations which can still cause organic-mineral binding will still be present. We have also shown that even at cation ratios heavily biased to the non-binding $\mathrm{Na}^{+}$cation, small concentrations of binding ion will still dominate, further informing the design of controlled salinity water for flooding. This is consistent with molecular dynamics simulations which suggested that cation bridging to montmorillonite would occur independent of salt concentration due to unhydrated cations in the Stern layer. ${ }^{38}$

Two of the mechanisms commonly offered to explain low salinity enhanced oil recovery are multivalent ion exchange and double layer expansion. We have shown that for the system of the AOT anion bridged to mica by either calcium or magnesium ions, neither of these mechanisms is required for organic release. Layers bridged by either of these ions showed complete desorption when both the ionic strength and bridging ion concentration were maintained constant but the organic component was removed from solution, suggesting that the bridged organic is only weakly bound and in rapid equilibrium with the species in the bulk solution. It is sufficient to simply remove this free organic to facilitate layer desorption. As the calcium to sodium ratio is well above the lowest ratio at which binding was still observed, it is not the case that the increased sodium concentration out-competes the calcium for either the $\mathrm{AOT}^{-}$or the mica surface.

The sulfonate head group of the $\mathrm{AOT}^{-}$anion is very strongly acidic; the pKa of the structurally similar methanesulfonic acid is approximately $-1.9{ }^{39}$ The pKa can be related to the strength of binding between the anion and an associated cation. As the $\mathrm{AOT}^{-}$anion shows such stability, the binding to any cation (and therefore the cation mediated binding to the surface) may be weaker than for an anion with a more positive pKaH. Organic carboxylic acids, which are commonly present in crude oils, ${ }^{40}$ have significantly higher pKa values (eg. for acetic acid pKa $=4 \cdot 8^{39}$ ). It may be the case that if these higher pKa groups adsorb in 
a cation mediated fashion to the anionic surface, they will adsorb in a less reversible fashion due to the stronger binding between anionic head group and cation. This would be more comparable to the observed adsorption behaviour of cationic molecules to mica, ${ }^{18}$ which were seen to persist even when the bulk organic was removed. The charge density of the anionic group may also be important in determining bridging behaviour; a more charge dense group with less delocalised charge will have a higher pKa but is also likely to be more strongly hydrated, so it may be less favourable for these groups to lose solvation and bridge via a cation.

We have not observed bridging interactions occurring below the $\mathrm{CMC}$ of the relevant surfactant system. This is also in contrast to the case of cationics on mica where adsorption occurred from 0.5 CMC in a complete layer, ${ }^{41}$ and provides further evidence that the strength of binding in the system under study is significantly weaker than for cationic surfactant adsorption.

\section{Conclusions}

In this work we have shown that the $\mathrm{AOT}^{-}$anion will bind to the anionic mica surface, even when present as a solution of the sodium salt, when cations capable of facilitating the binding interaction are added. We have demonstrated that as well as the common divalent ions $\mathrm{Ca}^{2+}$ and $\mathrm{Mg}^{2+}$, the prevalent monovalent ion $\mathrm{K}^{+}$also exhibits a binding interaction and facilitates adsorption. The reasons for the differences between this behaviour and that of the $\mathrm{Na}^{+}$ion, which does not cause binding, have been discussed and it was seen that even at high concentration ratios of $\mathrm{Na}^{+}$to $\mathrm{Ca}^{2+}$ (100:1) binding still occurred. The structures of the adsorbed layers at a condition of constant ionic strength have been proposed, and we have shown that despite maintaining ionic strength and binding ion concentration that if the organic component is removed from solution the adsorbed layers do not persist, showing an equilibrium between adsorbed and bulk species. 


\section{Acknowledgement}

We thank EPSRC and BP plc for the funding (RG8620) that made this work possible. We also thank the ILL (9-10-1545, DOI:10.5291/ILL-DATA.9-10-1545), ${ }^{42}$ ISIS (RB1820049, DOI: 10.5286/ISIS.E.99688055), and the beamtime committees for their allocations of time. We also thank the invaluable beamline scientists for their support and expertise.

\section{Supporting Information}

Reflectivity data, fitted reflectivity profiles, and fitted parameters to the additional bare mica substrates used

\section{References}

(1) Paria, S.; Khilar, K. C. A review on experimental studies of surfactant adsorption at the hydrophilic solid-water interface. Advances in Colloid and Interface Science $\mathbf{2 0 0 4}$, 110, 75-95.

(2) Wang, X.; Lee, S. Y.; Miller, K.; Welbourn, R.; Stocker, I.; Clarke, S.; Casford, M.; Gutfreund, P.; Skoda, M. W. A. Cation bridging studied by specular neutron reflection. Langmuir 2013, 29, 5520-5527.

(3) Griffin, L. R.; Browning, K. L.; Lee, S. Y.; Skoda, M. W.; Rogers, S.; Clarke, S. M. Multilayering of Calcium Aerosol-OT at the Mica/Water Interface Studied with Neutron Reflection: Formation of a Condensed Lamellar Phase at the CMC. Langmuir 2016, 32, 13054-13064.

(4) Arnason, T. S.; Keil, R. G. Adsorption of marine pore water organic matter to montmorillonite. Marine Chemistry 2000, 71, 309-320. 
(5) Buckley, J. S.; Liu, Y. Some mechanisms of crude oil/brine/solid interactions. Journal of Petroleum Science and Engineering 1998, 20, 155-160.

(6) Allen, F. J.; Griffin, L.; Alloway, R. M.; Gutfreund, P.; Lee, S. Y.; Truscott, C. L.; Welbourn, R. J. L.; Wood, M. H.; Clarke, S. M. Anionic Surfactants on Anionic Substrate: Monovalent Cation Binding. Langmuir 2017, 33, 7881-7888.

(7) Nave, S.; Eastoe, J.; Penfold, J. What is so special about Aerosol-OT? 1. Aqueous systems. Langmuir 2000, 16, 8733-8740.

(8) Stocker, I. N.; Miller, K. L.; Welbourn, R. J.; Clarke, S. M.; Collins, I. R.; Kinane, C.; Gutfreund, P. Adsorption of Aerosol-OT at the calcite/water interface - Comparison of the sodium and calcium salts. Journal of Colloid and Interface Science 2014, 418, $140-146$.

(9) Eastoe, J.; Fragneto, G.; Robinson, B. H.; Towey, T. F.; Heenan, R. K.; Leng, F. J. Variation of surfactant counterion and its effect on the structure and properties of Aerosol-OT-based water-in-oil microemulsions. Journal of the Chemical Society, Faraday Transactions 1992, 88, 461.

(10) Neasham, J. J. W. The Morphology Of Dispersed Clay In Sandstone Reservoirs And Its Effect On Sandstone Shaliness Pore Space And Fluid Flow Properties. SPE Annual Fall Technical Conference and Exhibition of the Society of Peteroleum Engineers of AIME 1977, 8 pp.

(11) Puntervold, T.; Mamonov, A.; Aghaeifar, Z.; Frafjord, G. O.; Moldestad, G. M.; Strand, S.; Austad, T. Role of Kaolinite Clay Minerals in Enhanced Oil Recovery by Low Salinity Water Injection. Energy and Fuels 2018, 32, 7374-7382.

(12) De Poel, W.; Pintea, S.; Drnec, J.; Carla, F.; Felici, R.; Mulder, P.; Elemans, J. A.; Van Enckevort, W. J.; Rowan, A. E.; Vlieg, E. Muscovite mica: Flatter than a pancake. Surface Science 2014, 619, 19-24. 
(13) Schlegel, M. L.; Nagy, K. L.; Fenter, P.; Cheng, L.; Sturchio, N. C.; Jacobsen, S. D. Cation sorption on the muscovite $\left(\begin{array}{lll}0 & 0 & 1\end{array}\right)$ surface in chloride solutions using highresolution X-ray reflectivity. Geochimica et Cosmochimica Acta 2006, 70, 3549-3565.

(14) Speranza, F.; Pilkington, G. A.; Dane, T. G.; Cresswell, P. T.; Li, P.; Jacobs, R. M. J.; Arnold, T.; Bouchenoire, L.; Thomas, R. K.; Briscoe, W. H. Quiescent bilayers at the micaâĂŞwater interface. Soft Matter 2013, 9, 7028.

(15) Striolo, A.; Grady, B. P. Surfactant Assemblies on Selected Nano-Structured Surfaces : Evidence, Driving Forces, and Applications. Langmuir 2017,

(16) Penfold, J.; Thomas, R. K. The application of the specular reflection of neutrons to the study of surfaces and interfaces. Journal of Physics: Condensed Matter 1990, 2, $1369-1412$.

(17) Briscoe, W. H.; Speranza, F.; Li, P.; Konovalov, O.; Bouchenoire, L.; Van Stam, J.; Klein, J.; Jacobs, R. M.; Thomas, R. K. Synchrotron XRR study of soft nanofilms at the mica-water interface. Soft Matter 2012, 8, 5055-5068.

(18) Browning, K. L.; Griffin, L. R.; Gutfreund, P.; Barker, R. D.; Clifton, L. A.; Hughes, A.; Clarke, S. M. Specular neutron reflection at the mica/water interface - Irreversible adsorption of a cationic dichain surfactant. Journal of Applied Crystallography 2014, $4 \%, 1638-1646$.

(19) Griffin, L. R.; Browning, K. L.; Truscott, C. L.; Clifton, L. a.; Clarke, S. M. Complete Bilayer Adsorption of C16TAB on the Surface of Mica Using Neutron Reflection. The Journal of Physical Chemistry B 2015, 119, 6457-6461.

(20) Saerbeck, T.; Cubitt, R.; Wildes, A.; Manzin, G.; Andersen, K. H.; Gutfreund, P. Recent upgrades of the neutron reflectometer D17 at ILL. Journal of Applied Crystallography 2018, 51, 249-256. 
(21) Dalgliesh, R. M.; Langridge, S.; Plomp, J.; De Haan, V. O.; Van Well, A. A. Offspec, the ISIS spin-echo reflectometer. Physica B: Condensed Matter. 2011; pp 2346-2349.

(22) Cubitt, R.; Saerbeck, T.; Campbell, R. A.; Barker, R.; Gutfreund, P. An improved algorithm for reducing reflectometry data involving divergent beams or non-flat samples. Journal of Applied Crystallography 2015, 48, 2006-2011.

(23) Gutfreund, P.; Saerbeck, T.; Gonzalez, M. A.; Pellegrini, E.; Laver, M.; Dewhurst, C.; Cubitt, R. Towards generalized data reduction on a chopperbased time-of-flight neutron reflectometer. Journal of Applied Crystallography 2018, 51, 606-615.

(24) Taylor, J. et al. Mantid, A high performance framework for reduction and analysis of neutron scattering data. Bulletin of the American Physical Society 2012, Volume 57,.

(25) Li, Z. X.; Lu, J. R.; Thomas, R. K.; Penfold, J. Neutron Reflectivity Studies of the Adsorption of Aerosol-OT at the AirâLŠWWater Interface: The Structure of the Sodium Salt. The Journal of Physical Chemistry B 1997, 101, 1615-1620.

(26) Chakraborty, A.; Chakraborty, S.; Saha, S. K. Temperature dependant micellization of AOT in aqueous medium: Effect of the nature of counterions. Journal of Dispersion Science and Technology 2007, 28, 984-989.

(27) Li, Z. X.; Lu, J. R.; Thomas, R. K. Neutron Reflectivity Studies of the Adsorption of Aerosol-OT at the Air/Water Interface: The Surface Excess. Langmuir 1997, 13, $3681-3685$.

(28) Satake, I.; Iwamatsu, I.; Hosokawa, S.; Matsuura, R. Surface activities of bivalent metal alkyl sulfates. I. The micelles of some metal alkyl sulfates. Bull. Chem. Soc. Jpn. 1963, $36,204-209$.

(29) Allen, F. J.; Truscott, C. L.; Welbourn, R. J.; Clarke, S. M. Anionic surfactant induced desorption of a cationic surfactant from mica. Applied Clay Science 2018, 160, 276-281. 
(30) Fragneto, G.; Li, Z. X.; Thomas, R. K.; Rennie, A. R.; Penfold, J. A Neutron Reflectivity Study of the Adsorption of Aerosol-OT on Self-Assembled Monolayers on Silicon. Journal of Colloid and Interface Science 1996, 178, 531-537.

(31) Thomas, R. K.; Penfold, J. Multilayering of Surfactant Systems at the Air-Dilute Aqueous Solution Interface. Langmuir 2015, 31, 7440-7456.

(32) Tucker, I. M.; Li, P.; Penfold, J.; Petkov, J. T.; Sivia, D. S.; Xu, H.; Thomas, R. K. Multivalent-Counterion-Induced Surfactant Multilayer Formation at Hydrophobic and Hydrophilic SolidâĂŞSolution Interfaces. Langmuir 2015, 31, 6773-6781.

(33) Xu, H.; Thomas, R.; Penfold, J.; Li, P.; Ma, K.; Welbourne, R.; Roberts, D.; Petkov, J. The impact of electrolyte on the adsorption of the anionic surfactant methyl ester sulfonate at the air-solution interface: Surface multilayer formation. Journal of Colloid and Interface Science 2018, 512, 231-238.

(34) Kobayashi, K.; Liang, Y.; Murata, S.; Matsuoka, T.; Takahashi, S.; Amano, K.-I.; Nishi, N.; Sakka, T. Stability Evaluation of Cation Bridging on Muscovite Surface for Improved Description of Ion-Specific Wettability Alteration. The Journal of Physical Chemistry C 2017, 121, 9273-9281.

(35) Tan, Q.; Zhao, G.; Qiu, Y.; Kan, Y.; Ni, Z.; Chen, Y. Experimental observation of the ion-ion correlation effects on Charge inversion and strong adhesion between mica surfaces in aqueous electrolyte solutions. Langmuir 2014, 30, 10845-10854.

(36) de Poel, W.; Vaessen, S. L.; Drnec, J.; Engwerda, A. H.; Townsend, E. R.; Pintea, S.; de Jong, A. E.; Jankowski, M.; Carlà, F.; Felici, R.; Elemans, J. A.; van Enckevort, W. J.; Rowan, A. E.; Vlieg, E. Metal ion-exchange on the muscovite mica surface. Surface Science 2017, 665, 56-61.

(37) Mohammad Salehi, M.; Omidvar, P.; Naeimi, F. Salinity of injection water and its 
impact on oil recovery absolute permeability, residual oil saturation, interfacial tension and capillary pressure. Egyptian Journal of Petroleum 2017, 26, 301-312.

(38) Underwood, T.; Erastova, V.; Cubillas, P.; Greenwell, H. C. Molecular dynamic simulations of montmorillonite organic interactions under varying salinity: An insight into enhanced oil recovery. Journal of Physical Chemistry $C$ 2015, 119, 7282-7294.

(39) Serjeant, E.; Dempsey, B. IUPAC Chemical Data Series; Pergamon Press, 1979; p 998.

(40) Andersen, S. I.; Chandra, M. S.; Chen, J.; Zeng, B. Y.; Zou, F.; Mapolelo, M.; Abdallah, W.; Buiting, J. J. Detection and Impact of Carboxylic Acids at the Crude Oil-Water Interface. Energy and Fuels 2016, 30, 4475-4485.

(41) Griffin, L. R.; Browning, K. L.; Truscott, C. L.; Clifton, L. A.; Webster, J.; Clarke, S. M. A comparison of didodecyldimethylammonium bromide adsorbed at mica/water and silica/water interfaces using neutron reflection. Journal of Colloid and Interface Science 2016, 478, 365-373.

(42) Allen, F. J.; Clarke, S. M.; Gutfreund, P.; Truscott, C. L. Adsorption of an anionic surfactant on anionic surfaces in the presence of mono and divalent ions. 2018; https: //doi.ill.fr/10.5291/ILL-DATA.9-10-1545. 
Graphical TOC Entry

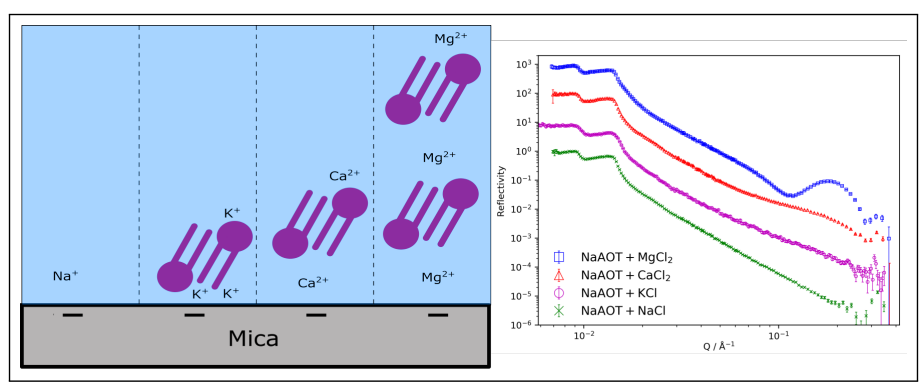

